\title{
Closed Intubation with Mitomycin C Application for Nasolacrimal Duct Obstruction Patients beyond the Age of Two Years
}

\author{
Hossam Z* \\ Al Azhar University, Egypt \\ *Corresponding author: Hossam Ziada, Al Azhar University, 1 Sobhi Housain \\ building, 5th settlement, New Cairo, Egypt, Tel: 00201227578669; E-mail: \\ Drhossam669@yahoo.com
}

Research Article

Volume 3 Issue 2

Received Date: January 19, 2018

Published Date: February 09, 2018

\section{Abstract}

Purpose: to explore safety and efficacy of adding Mitomycin C to intubation in prevention of recurrence and increasing the success rate of closed intubation in patients beyond the age of 2 years.

Patients and methods: Prospective study included thirty eyes of 24 consecutive patients with tearing and discharges due to primary and acquired partial NLD obstruction, their ages were from 2.5 to 40 years, Male/Female ratio was 10/14. Probing of NLD with SI (which is soaked in Mitomycin C $0.2 \mathrm{mg} / \mathrm{ml}$ for 2 minutes) was done in all cases, but it was abandoned if the resistance or obstruction was too difficult to overcome or if excessive bleeding or a hard blind bony pouch at the end of the nasal lacrimal duct was found ( 5 patients). In these patients, DCR was performed, and these patients were excluded from our study.

Results: The procedure was successful in 24 eyes and unsuccessful in 6 eyes. The mean age of the patients with unsuccessful outcomes was $22.4 \pm 3.4$ years, whereas that of the patients with successful outcomes was $8.0 \pm 2.8$ years and the difference was statistically significant $(\mathrm{P}=0.006)$. Gender and time at mean silicone tube removal (both $\mathrm{P}>0.05)$ were not statistically different. No serious intra- and/or post-operative complications including excessive bleeding, punctal damage, 'cheese wiring', dacryocystitis, or pyogenic granuloma formation were observed.

Conclusion: The results of our prospective study showed that SI with MMC in patients with simple epiphora has a success rate of $80 \%$. This success rate was achieved by other studies using SI alone, but in younger age group. In our study, we include elder patient group with almost the same success rate. So, we can conclude that MMC application during SI does not appear to have additional benefit over SI alone in young children with simple epiphora. While the application of MMC during SI would result in better efficacy compared to SI alone in older ages

Keywords: Ductal Obstruction; Dacryocyctitis; Intubation; Tearing; Mitomycin C 


\section{Open Access Journal of Ophthalmology}

\section{Introduction}

Nasolacrimal duct obstruction is a blockage of the lacrimal drainage system. In children the majority of nasolacrimal duct obstruction is congenital. Congenital nasolacrimal duct obstruction (CNLDO) occurs in approximately $5 \%$ of normal newborn infants. The blockage occurs most commonly at the valve of Hasner at the distal end of the duct. There is no sex predilection and no genetic predisposition. The blockage can be unilateral or bilateral. The rate of spontaneous resolution is estimated to be $90 \%$ within the first year of life. While in older children or adults, it may be due to improperly treated CNLDO or recurrent dacryocyctitis.

Probing and syringing of the tear duct may be necessary for children with persistent watery eyes and recurrent conjunctivitis [1-3]. One or both eyes may be affected.

Probing and syringing is usually a quick procedure where a fine probe is passed through the tear duct to clear the blockage or to widen the tear duct. Sometimes a dye is then passed through to check that the duct is clear. If this procedure failed to clear the Tear duct blocks, a procedure called intubation will be needed.

During intubation, two small wire probes attached to silicone tubes are passed into the upper and lower tear duct openings (puncta) and down the tear duct drainage system into the nasal cavity. The wires are removed and the tubes are tied or sewn in place to keep the tear ducts open. Intubation is usually done as part of a probing procedure in the hospital using general anesthesia. Most people go home the same day.

From 3 to 16 weeks after surgery, the person returns to the doctor's office, and the tubes are removed. Anesthesia is usually not needed when the tubes are taken out.

Some doctors leave the tubes in place for 6 months to a year. This causes a new lining to form around the tubes, leaving an open channel in the tear duct when the tubes are removed.

Intubation leaves no facial scars. And it has less risk of complications than dacryocystorhinostomy, a procedure that creates a new tear duct canal. Intubation is sometimes used when a person:

- Has a partial blockage of a tear duct.

- Has had one or more failed probing attempts and who still has tear duct block symptoms.

- Wants to avoid the surgical incision (on the face) that results from dacryocystorhinostomy.

- Has had dacryocystorhinostomy surgery, and the tear duct has become blocked again.

Risks of intubation include the following:

- The tube may loosen and move out of place.

- The hole in the corner of the eyelid through which tears drain (punctum) may be damaged.

- The lining of the eyelids (conjunctiva) may become irritated.

- The person may feel discomfort inside his or her nose.

It is common to have a watery eye after surgery. Tears cannot drain as well through the affected tear duct while the very small tubes from the intubation are still in place. Silicone intubation (SI) is indicated in the treatment of congenital and acquired NLDO, with a success rate ranging from $63 \%$ to $100 \%$. This procedure is particularly successful in mild to moderate obstruction, and uncomplicated cases.

Since introduction by Chen, MMC has been used in many ocular procedures to reduce scarring and to enhance the success rate. Its application in lacrimal surgery has been studied by some authors. Liu and Bosley studied SI of the NLD with MMC but did not have beneficial results. In this prospective study, we aimed at evaluating the efficacy of MMC treated SI technique in patients who may have undergone a DCR as an alternative procedure considering protocols of the Liu and Bosley study.

\section{Patients and Methods}

Thirty eyes of 24 consecutive patients their ages were from 2.5 to 40 years, Male/Female ratio was10/14. All patients were with a chief symptom of tearing and discharge due to primary and acquired partial NLD obstruction who were potential candidate closed intubation were included in our study between February 2015 and April 2016. Ethical approval is obtained from the ethical committee of Al Azhar University. Only patients with primary and acquired NLD obstruction, with partial obstruction, negative regurge, and positive Jons fluoresce in test, were included in the study (Table 1 and Figure 1). 


\section{Open Access Journal of Ophthalmology}

\begin{tabular}{|c|c|}
\hline & Total $(\mathbf{N}=\mathbf{2 4})$ \\
\hline Age (years) & $2.5-40(21.7 \pm 2.5)$ \\
\hline Sex & \\
\hline Male & $10(41.7 \%)$ \\
\hline Female & $14(58.3 \%)$ \\
\hline Mean follow-up period & $6-10(6.8 \pm 2.4)$ \\
\hline Silicone tube removal time & $3-5(3.2 \pm 1.1)$ \\
\hline
\end{tabular}

Table 1: Descriptive data of the study group.

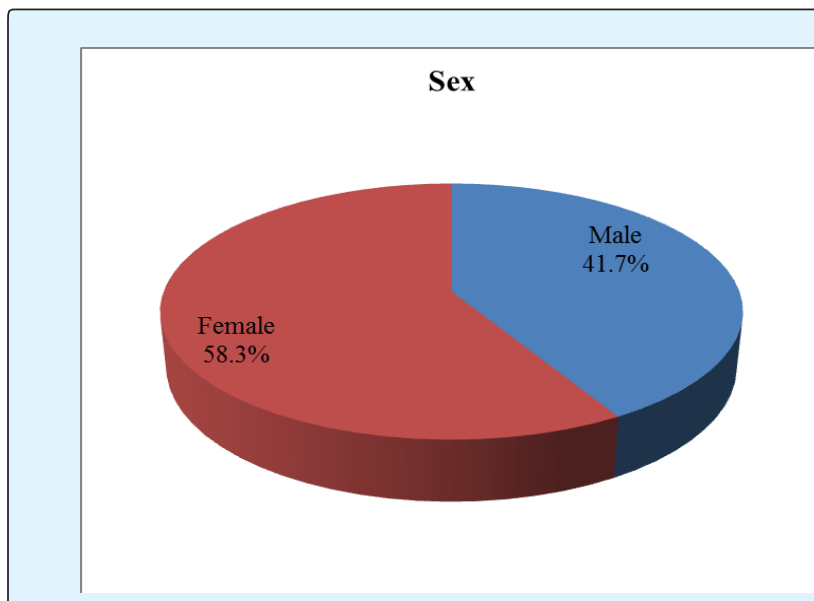

Figure 1: Sex pie chart distribution of the study group.

Patients with symptoms secondary to identifiable or treatable causes such as dry eyes, lid abnormalities (trichiasis, distichiasis, entropion, ectropion, lid laxity), glaucoma, refractive error, tumor of the eyelid, and secondary causes of NLD obstruction such as fractures of the facial bones, nose structural abnormalities, severe atrophic rhinitis, tumors of the lacrimal system, canalicular and common canalicular obstruction, and previously failed DCR were excluded.

Informed consent was obtained from all patients. Preoperative work-up including obtaining patient medical and ocular history, visual acuity, thorough slit-lamp examination of the conjunctiva and cornea to rule out possible ocular surface disorders, was performed. The eyelids were examined for proper closure and possible laxity or misdirected lashes. Whenever needed, Schirmer I and II tests tear break-up time, Jones test I, or a dye disappearance test, and fluoresce in staining were performed. Regurge test is also performed; the patients with positive regurge were excluded. Irrigation with saline solution revealed the nature and location of the obstruction.

\section{Surgical Technique}

The procedure was performed under general anesthesia in all patients. Blunt-tipped probe was used to dilate and for probing of both the upper and lower puncta. A Crawford SI set (BD Visitec, 27 gauge) was used in all patients. If resistance was felt, its location was recorded. Probing of NLD with SI (which is soaked in Mitomycin C $0.2 \mathrm{mg} / \mathrm{ml}$ for 2 minutes) was abandoned if the resistance or obstruction was too difficult to overcome or if excessive bleeding or a hard blind bony pouch at the end of the nasal lacrimal duct was found (5 patients). In these patients, DCR was performed, and these patients were excluded from our study. After overcoming the obstruction, the Crawford silicone was slightly withdrawn and then does suctioning the nasal cavity. Care of the soaked silicon tube with MMC was taken so that there was no spill over the cornea, and constant corneal irrigation with saline solution was given during this period. Copious irrigation with gentle suctioning followed, and SI proceeded in the usual manner.

After surgery, a small amount of tetracycline ointment was instilled in the operated eye. Patients after surgery, received betamethasone eye drops 6 hourly, chloramphenicol eye drops 4 hourly that after 1 week were tapered. Patients also received oral cephalexin for 1 week. Follow-up visits were scheduled at 1 week, 1, 3, and 6-months postoperative intervals.

During each visit, the same relevant lacrimal function tests were repeated and failures were recorded. In documented failed cases, DCR was offered if the patient's symptoms could not be managed with nonsurgical managements. The silicone was left in place for 3 months. Any complication during this time was recorded and managed appropriately. After completion of the study, all records were reviewed and analyzed. Statistical evaluations included means analysis with the one-way analysis of variance test with the Student-Newman-Keuls test. Success rates were analyzed by two-tailed chi-square test. A p value less than 0.05 were regarded as significant.

\section{Results}

The mean age was $21.7 \pm 2.5$ years (ranging from 2.5 to 40 years). Of the 24 patients, 10 were male and 14 were female. All patients had initiation of symptoms of chronic NLDO within the several months before surgery with repeated medical treatment trials. A bicanalicular MMC soaked silicone tube $(0.2 \mathrm{mg} / \mathrm{ml}$ for 2 minutes $)$ was 


\section{Open Access Journal of Ophthalmology}

successfully placed in all patients. Inferior turbinate infracture was required in two $(6 \%)$ of the cases. The operation was classified as successful by absence of epiphora or discharge, patent NLD in irrigation test, and the patient to be symptom free 6 months after removal of the silicone tube (Table 1).

The mean follow-up period was $6.8 \pm 2.4$ months (ranging from 6 to 10 months). The mean silicone tube removal time was $3.2 \pm 1.1$ months (ranging from 3 to 5 months).

Although the silicone tubing was well-tolerated in the most of the cases, three patients $(10 \%)$ experienced epiphora and minimal mucopurulent secretion with the tubes in place which resolved after the removal of the tubes. The complete resolution of signs and symptoms with dye disappearance test grade $0-1$ was observed in 24 of 30 eyes $(80 \%)$ during the follow-up period. In six cases $(20 \%)$, improvement of the signs and symptoms could not be achieved after the procedure, one case (3.3\%) developed lacrimal fistula at site of medial can thus 3 weeks after surgery, which was treated conservatively, then shifted to DCR. While in the other five cases, signs and symptoms of epiphora and discharge remain with the tube as well as its removal.

So the procedure was successful in 24 eyes and unsuccessful in 6 eyes. The mean age of the patients with unsuccessful outcomes was $22.4 \pm 3.4$ years, whereas that of the patients with successful outcomes was $8.0 \pm 2.8$ years and the diff difference was statistically significant $(\mathrm{P}=0.006)$. Gender and time at mean silicone tube removal (both $\mathrm{P}>0.05$ ) were not statistically different. No serious intra- and/or post-operative complications including excessive bleeding, punctal damage, 'cheese wiring', dacryocystitis, or pyogenic granuloma formation were observed (Figure 2, Table 2).

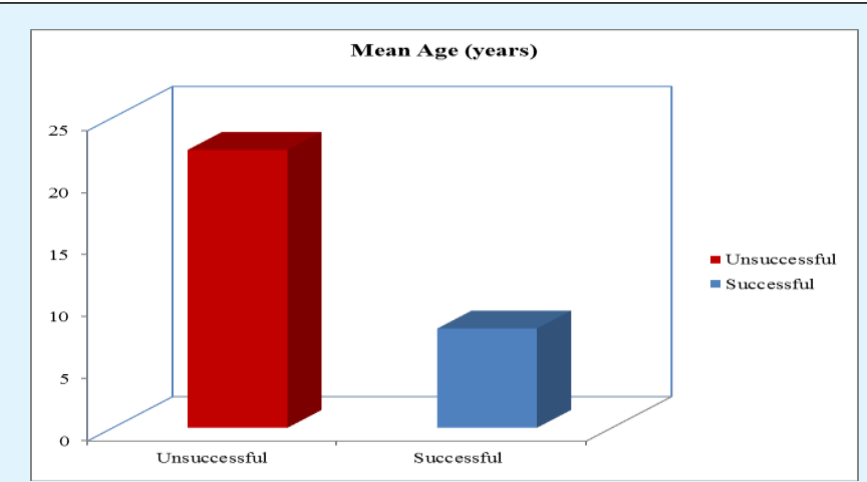

Figure 2: Bar chart between with unsuccessful and with successful outcomes according to mean age (years).

\begin{tabular}{|c|c|c|c|}
\hline Outcomes & Mean age (years) & t-test & p-value \\
\hline Unsuccessful & $22.4 \pm 3.4$ & 7.244 & 0.006 \\
\hline Successful & $8.0 \pm 2.8$ & & \\
\hline
\end{tabular}

Table 2: Comparison between with unsuccessful and with successful outcomes according to mean age (years).

This table shows statistically significant difference between with unsuccessful and with successful outcomes according to mean age (years).

\section{Discussion}

The present study showed that silicone intubation of nasolacrimal duct with nasal endoscopic visualization had favorable results as a primary treatment of persistent NLDO in elder children as well as adult patients with acquired NLDO.

Congenital NLDO is a common lacrimal system disorder in children. Conservative therapy has been found to be sufficient in most cases during the first 12 months and probing has been proposed as the most effective procedure in cases aged between 12 and 18 months. Although silicone intubation is generally used after failure of conservative therapy and probing, it has been suggested as the primary procedure in children older than 1.5-2 years, owing to the decreasing success of probing with age $[4,5]$. Silicone tubing avoids annular obstruction and contraction inside the nasolacrimal canal during wound healing, by acting as a temporary stent [6]. Previous studies have shown high success rates of silicone intubation in the treatment of CNLDO in children aged up to 7 years, and others showed higher failure rate beyond this age. Orhan, et al. used silicone intubation with the help of nasal endoscopic viewing in children with an age range of 18-48 months in the treatment of CNLDO [7-12]. They found a $100 \%$ success rate for a follow-up period ranging from 4 to 24 months. Repka, et al. reported a $90 \%$ success rate in children aged 6 to 45 months with no prior nasolacrimal surgical procedure [8,13]. Andalib, et al. achieved an $86.2 \%$ success rate for monocanalicular and an $89 \%$ success rate for bicanalicular silicone intubation in children younger than 7 years of age [10]. Okumus, et al. showed a success rate of $(73.3 \%)$, which was slightly lower than in the previous studies, probably owing to the fact that success of nasolacrimal duct intubation reduces with increasing age. In addition, in accordance with the previous studies, we showed that the mean age of the patients with unsuccessful results was significantly higher than that of the patients with successful results $[14,15]$. This may be caused by increased fibrosis at the site of obstruction in older children. 


\section{Open Access Journal of Ophthalmology}

Few studies have investigated the results of nasolacrimal duct silicone intubation in children with wider age ranges. Aggarwal, et al. achieved complete resolution of symptoms in $80 \%$ of patients, in a population including children with ages varied from 11 months to 9 years [16-18]. They stated that this approach might avoid a DCR in over $80 \%$ of children with epiphora. Kraft, et al. analyzed the outcomes of silicone intubations in children aged 6 months to 16 years and found an overall success rate of $80.3 \%$ [17]. However, in the aforementioned studies, no specific analysis for the patients older than 7 years were undertaken. To the best of our knowledge, we are the first in the literature to report the results of silicone intubation in children older than 16 years, and adults their ages were up to 40 years.

These are the success rates in different studies with different ranges of ages up to 16 years, but all of them were without addition of MMC. Our result was $80 \%$ success rate like that with Kraft, et al. and Agrawal, but in Kraft study, range of ages was between 6 months and 16 years, with Agrawal, range of ages was between 11 months and 9 years, while in our study, range of ages was between 2.5 and 40 years with the same success rate. The difference between our study and their studies is the use of MMC, which may be considered in increasing the success rate with increasing age of patients.

On the review of MMC usage with SI, Syed-Ziaeddin, et al. (Iranian J ophth) had carried out a randomized, prospective study using MMC during SI at concentrations of $0.2 \mathrm{mg} / \mathrm{ml}$ to evaluate its effect [19]. The success rate was $75.9 \%$ with (MMC+ SI). They also found that the duration of symptoms prior to surgery has an impact on the success rate even with MMC. Duration of symptoms prior to procedure in patients that had only epiphora without discharge well correlated with success rate, so that in control group, patients with less than 6 months of duration of symptoms had significantly better results (83.3\%) than patients with more than 6 months of symptoms (29.4\%). Addition of MMC to SI in patients with simple epiphora and less than 6 months of symptoms did not have additional effect on efficacy of treatment. However, in patients with simple epiphora and more than 6 months of symptoms, success rate in placebo group and SI+MMC group was $29.4 \%$ and $71.4 \%$, respectively. Ugurbas, et al. used $0.5 \mathrm{mg} / \mathrm{ml} \mathrm{MMC} \mathrm{for} 2.5$ minutes with good histopathologic effects [20]. You and Fang reported application of $0.2 \mathrm{mg} / \mathrm{ml} \mathrm{MMC} \mathrm{and} 0.5$ $\mathrm{mg} / \mathrm{ml} \mathrm{MMC} \mathrm{for} \mathrm{the} \mathrm{same} \mathrm{time} \mathrm{of} \mathrm{application} \mathrm{(5} \mathrm{minutes)}$ that yielded success rates of $100 \%$ and $94 \%$, respectively, without any complication [6]. Liu and Bosley used 0.2 $\mathrm{mg} / \mathrm{ml}$ MMC without any complication. Randomized studies involving variable dosing schemes and long-term follow-up visits would help to elucidate the optimum drug regimen. SI of the NLD in adults has a success rate ranging from $22 \%$ to $83 \%$. Liu and Bosley performed SI with MMC for complete NLDO in adults and found a 53\% success rate with a mean follow-up of 18 months. Angrist and Dortzbach found a $22.2 \%$ success rate for complete NLD obstruction and $77.8 \%$ for incomplete NLD obstruction following SI.27. The range of ages in Syed-Ziaeddin, et al. study was up to 30 years, and success rate in MMC group was $75.9 \%$, so, our study showed higher success rate of $80 \%$ with higher age, 40 year [19].

Limitations of the present study were the relative small sample size and short follow-up period. Studies with larger sample sizes, longer follow-up periods and, in addition, a similar study with monocanalicular intubation (as this would avoid the use of a second anaesthetic) would make useful contributions to the literature in the treatment of older children with persistent CNLDO.

\section{Conclusion}

In summary, the results of our prospective study showed that SI with MMC in patients with simple epiphora has a success rate of $80 \%$. This success rate was achieved by other studies using SI alone, but in younger age group. In our study, we include elder patient group with almost the same success rate.

So, we can conclude that MMC application during SI does not appear to have additional benefit over SI alone in young children with simple epiphora. While the application of MMC during SI would result in better efficacy compared to SI alone in older ages. In longer duration of symptoms of epiphora, application of MMC would increase success rate significantly, as compared with the other authors.

We recommend SI in patients with NLD obstruction and simple epiphora and no discharge when the eventual cosmetic outcome is important for them; SI alone is sufficient when the duration of symptoms is less than 6 months; SI with application of MMC is a better choice in patients with more than 6 months' duration of symptoms. We do not recommend these procedures in patients with chronic dacryocystitis and discharge. We also propose that a larger prospective study be conducted to more definitely evaluate the long term outcome. 


\section{Open Access Journal of Ophthalmology}

\section{References}

1. Schnall BM (2013) Pediatric nasolacrimal duct obstruction. Curr Opin Ophthalmol 24(5): 421-424.

2. Petersen RA, Robb RM (1978) The natural course of congenital obstruction of the nasolacrimal duct. J Pediatr Ophthalmol Strabismus 15(4): 246-250.

3. Stager D, Baker JD, Frey T, Weakley DR Jr, Birch EE (1992) Office probing of congenital nasolacrimal duct obstruction. Ophthalmic Surg 23(7): 482-484.

4. Katowitz JA, Welsh MG (1987) Timing of initial probing and irrigation in congenital nasolacrimal duct obstruction. Ophthalmology 94(6): 698-705.

5. Nelson LB, Calhoun JH, Menduke H (1985) Medical management of congenital nasolacrimal duct obstruction. Pediatrics 76(2): 172-175.

6. Paul TO, Shepherd R (1994) Congenital nasolacrimal duct obstruction: natural history and the timing of optimal intervention. J Pediatr Ophthalmol Strabismus 31(6): 362-367.

7. Migliori ME, Putterman AM (1988) Silicone intubation for the treatment of congenital lacrimal duct obstruction. Ophthalmology 95(6): 792-795.

8. Pediatric Eye Disease Investigator Group, Repka MX, Melia BM, Beck RW, Atkinson CS, Chandler DL, et al. (2008) Primary treatment of nasolacrimal duct obstruction with nasolacrimal duct intubation in children younger than 4 years of age. JAAPOS 12(5): 445-450.

9. Orhan M, Onerci M (1997) Intranasal endoscopic silicone intubation for congenital obstruction of the nasolacrimal duct in children. Int J Pediatr Otorhinolaryngol 41(3): 273-278.

10. Andalib D, Gharabaghi D, Nabai R, Abbaszadeh M (2010) Monocanalicular versus bicanalicular silicone intubation for congenital nasolacrimal duct obstruction. JAAPOS 14(5): 421-424.

11. Yazici B, Akarsu C, Salkaya M (2006) Silicone intubation with the Ritleng method in children with congenital nasolacrimal duct obstruction. J AAPOS 10(4): 328-332.

12. Al-Faky $\mathrm{YH}, \mathrm{Al}-$ Sobaie $\mathrm{N}$, Mousa $\mathrm{A}, \mathrm{Al}-$ Odan $\mathrm{H}, \mathrm{Al}-$ Huthail R, et al. (2012) Evaluation of treatment modalities and prognostic factors in children with congenital nasolacrimal duct obstruction. JAAPOS 16(1): 53-57.

13. Robb RM (1998) Success rates of nasolacrimal duct probing at time intervals after 1 year of age. Ophthalmology 105(7): 1307-1309.

14. Lueder GT (2002) Balloon catheter dilation for treatment of persistent nasolacrimal duct obstruction. Am J Ophthalmol 133(3): 337-340.

15. Welsh MG, Katowitz JA (1989) Timing of silastic tubing removal after intubation for congenital nasolacrimal duct obstruction. Ophthal Plast Reconstr Surg 5(1): 43-47.

16. Aggarwal RK, Misson GP, Donaldson I, Willshaw HE (1993) The role of nasolacrimal intubation in the management of childhood epiphora. Eye (Lond) 7(6): 760-762.

17. Kraft SP, Crawford JS (1982) Silikon tube intubation in disorders of the lacrimal system in children. Am J Ophthalmol 94(3): 290-299.

18. MacEwen CJ, Young JD (1991) The fluorescein disappearance test (FDT): an evaluation of its use in infants. J Pediatr Ophthalmol Strabismus 28(6): 302305.

19. Yeatts RP, Neves RB (1999) Use of mitomycin C in repeat dacryocystorhinostomy. Ophthal Plast Reconstr Surg 15(1): 19-22.

20. Chris E de Souza, Nisar J, de Souza RA (2012) Pediatric endoscopic dacryocystorhinostomy. Otolaryngol Head Neck Surg 147(2): 335-337.

21. Ali MJ, Gupta H, Naik MN, Honavar SG (2013) Endoscopic guided single self-linking silicone stent in pediatric external dacryocystorhinostomy. Minim Invasive Ther Allied Technol 22(5): 266-270. 